\title{
Author Spotlight: Morgan A. Sendzischew Shane
}

\section{Morgan A. Sendzischew Shane ${ }^{1}$}

Published online: 24 June 2020

(c) Springer Science+Business Media, LLC, part of Springer Nature 2020

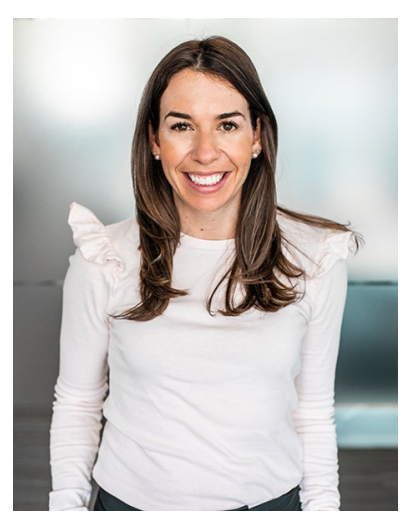

Morgan A. Sendzischew Shane, MD, is a Clinical Instructor and the first T32 Research Fellowship Candidate at the
University of Miami Miller School of Medicine Division of Gastroenterology. She completed her MD, internal medicine residency training, and gastroenterology fellowship at the University of Miami, where she is also pursuing her masters in clinical and translational science and investigation. She has a clinical interest in motility and women's health, and has focused research in the area of pelvic floor dysfunction as well as reflux and the microbiome. She also has an interest in medical education on all levels and currently serves as the co-clerkship director for the third year internal medicine clerkship.

Publisher's note Springer Nature remains neutral with regard to jurisdictional claims in published maps and institutional affiliations.

Morgan A. Sendzischew Shane

MSendz@med.miami.edu

1 Division of Gastroenterology, Department of Medicine, University of Miami Miller School of Medicine, Miami, FL, USA 